\title{
Pendekar (Penderes Badek Karangsari) Program CSR PT Pertamina (Persero) Fuel Terminal Maos
}

\author{
Faries Fardian A. ${ }^{1}$, Ardi Maulana M. ${ }^{2}$, Faishol Adib T. ${ }^{3}$, Della \\ N. ${ }^{4}$, Aldita Cindy ${ }^{5}$ \\ Tim Community Development dan Environmental Fuel Terminal Maos
}

1Faries.anggoma@pertamina.com, 2Ardi.mubarok@pertamina.com, 3Faisholat@outlook.com, 4Nirmaladella13@gmail.com, ${ }^{4}$ Acindya.arf@gmail.com

Submitted: 2021-05-18 | Revised: 2021-06-03 | Accepted: 2021-06-07

\begin{abstract}
The potential for coconut sugar production in the Karangsari Village Area, Adipala District, Cilacap Regency is quite large. The market potential, both domestic and export, is quite large, so it needs assistance so that the product is ready to be marketed. The implementation of the CSR program from PT Pertamina (Persero) Fuel Terminal Maos, based on local potential and culture, namely the manufacture of coconut sugar in Karangsari Village named Pendekar (Penderes Badek Karangsari). In collaboration with several parties, namely the Nira Cahaya Sejahtera Cooperative and the Karangsari Village Government. Some of the problems faced by the tappers group are still using the chemical sulfuric acid, using firewood for cooking and using used PVC paint cans. The solution is Pertamina Fuel Terminal Maos replacing the use of sulfide to laru use, initiating the conversion to gas fuel, namely $12 \mathrm{~kg}$ LPG and helping to replace the paint cans used as pongkor using food grade pongkor. The results of the CSR Program of Fuel Terminal Maos hopes that Karangsari Village Ants Sugar Products can reach a wider market share, not only domestically but also abroad. As well as raising the economy of the people of Karangsari Village through the Pendekar program.
\end{abstract}

Keywords: Pertamina, Fuel Terminal Maos, CSR, Penderes.

Abstrak. Potensi produksi gula kelapa di Wilayah Desa Karangsari Kecamatan Adipala, Kabupaten Cilacap cukup besar. Diperlukan pendampingan agar produk siap dipasarkan hingga ekspor. Pelaksanaan program CSR dari PT.Pertamina (Persero) Fuel Terminal Maos berbasis potensi dan budaya lokal yaitu pembuatan gula kelapa di Desa Karangsari yang dikemas dengan program Pendekar. Bekerjasama dengan beberapa pihak yaitu Koperasi Nira Cahaya Sejahtera dan Pemerintah Desa Karangsari. Beberapa permasalahan yang dihadapi kelompok penderes yaitu masih menggunakan bahan kimia Sulfid, menggunakan kayu bakar untuk memasak dan menggunakan kaleng PVC bekas cat. Solusinya Pertamina Fuel Terminal Maos mengganti penggunaan sulfid ke penggunaan laru, menginisiasi untuk mengkonversi ke bahan bakar gas yaitu LPG $12 \mathrm{~kg}$ dan membantu penggantian kaleng cat yang digunakan sebagai pongkor tersebut 
menggunakan pongkor food grade. Hasil Program CSR PT Pertamina (Persero) Fuel Terminal Maos mengharapkan Produk Gula Semut Desa Karangsari dapat mencapai pangsa pasar yang lebih luas lagi, tidak hanya didalam negeri namun hingga luar negeri. Serta mengangkat perekonomian masyarakat Desa Karangsari melalui program Pendekar.

Kata Kunci: Pertamina, Fuel Terminal Maos, CSR, Penderes.

\section{Pendahuluan}

Gula Kelapa memiliki beberapa manfaat bagi kesehatan., ${ }^{1,2}$ Terutama bagi penderita diabetes karena mengandung insulin yang membantu memperlambat penyerapan glukosa ${ }^{3}$ sehingga baik dikonsumsi para penderita diabetes. Memiliki kandungan fluktosa yang rendah dan kadar indeks glikemik menjadikan gula kelapa ini sebagai gula alternatif yang lebih baik. ${ }^{4}$ Potensi produksi gula kelapa di Wilayah Desa Karangsari Kecamatan Adipala, Kabupaten Cilacap cukup besar. Terdapat 40 orang dalam kelompok Karangsari Jaya yang masing-masing dapat memproduksi gula kelapa mencapai empat hingga lima kilogram perhari. ${ }^{5}$ Saat ini kelompok pengrajin gula di naungi oleh Koperasi Nira sebagia mitra dalam mendistribusikan penjualan.

Potensi pasar baik dalam negeri hingga ekspor cukup besar bagi produksi gula kelapa sehingga penderes memerlukan pendampingan agar produk mereka siap dipasarkan ke jangkauan yang lebih luas lagi. Untuk memasarkan produk lebih luas lagi, terdapat beberapa hambatan yang dialami kelompok penderes dan juga Koperasi Nira Cahaya. Mulai dari penggunaan bahan kimia sulfid tidak sesuai takaran dalam proses produksi yang akan memiliki dampak buruk jangka panjang bila dikonsumsi secara terus menerus ${ }^{6,7}$

1 Wardhana, Irawan Wisnu, and M.Arief Budihardjo. 2019. "Pembuatan Gula Semut Kelapa Jahe Di Desa Ujung-Ujung Kec.Pabelan Kab. Semarang.” Jurnal Pasopati 1 (2): 51-55.

2 Zuliana, Crysse, Endrika Widyastuti, and Wahono Hadi Susanto. 2016. "Pembuatan Gula Semut Kelapa (Kajian PH Gula Kelapa Dan Konsentrasi Natrium Bikarbonat)." Jurnal Pangan Dan Agroindustri 4 (1): 109-19. https://jpa.ub.ac.id/index.php/jpa/article/view/311.

${ }^{3}$ Pratama, F., W.H. Susanto, and I. Purwantiningrum. 2015. "Pembuatan Gula Kelapa Dari

Nira Terfermentasi Alami (Kajian Pengarub Konsentrasi Anti Inversi Dan Natrium Metabisulfit)." Jurnal Pangan dan Agroindustri 3 (4): 1272-82.

${ }^{4}$ Joseph, G H, and Payung Layuk. 2012. "Pengolahan Gula Semut Dari Aren." Buletin Palma 13 (1): 60-65. https://doi.org/10.21082/bp.v13n1.2012.60-65.

5 Hromly. 2019. "Gula Semut Cilacap di Eksport Ke Belanda." Https://Jatengprov.Go.Id/. 2019. https://jatengprov.go.id/beritadaerah/gula-semut-cilacapdi-eksport-ke-belanda/.

${ }^{6}$ Rosanti, Aulia Dewi. 2016. "Pengarub Penambahan Dosis Natrium Bisulfit Dan Natrium Metabisulfit Terbadap Kualitas Gula Merah Tebu.” Jurnal Hijau Cendekia 1 (1): 6-10.

7 Akolo, Ingka Rizkyani, and Rosdiani Azis. 2018. "Analisis Pengarub Natrium Metabisulfit (Na252O5) Dan Lama Penyimpanan Terhadap Proses Browning Buah Pir Menggunakan Rancangan Faktorial." Jurnal Technopreneur (JTech) 5 (2): 54. https://doi.org/10.30869/jtech.v5i2.137. 
dan juga memiliki dampak paparan konsentrasi rendah bila langsung bersentuhan dengan kulit. ${ }^{8}$ Sehingga diperlukan pendampingan penggunaan sulfid yang tepat atau mengganti penggunaan sulfid ke bahan lainnya yang lebih aman untuk dikonsumsi. Penggunaan kayu bakar untuk memasak gula masih digunakan para penderes tradisional yang akan berdampak berapa kayu yang perlu ditebang untuk memproduksi gula. Permasalahan ketiga yang dihadapi para penderes tradisional adalah penggunaan kaleng PVC bekas cat, dimana kaleng tersebut tidak memenuhi standar food grade. Sehingga mempersulit saat akan diverifikasi organik. Peningkatan mutu produksi dan pemasaran untuk pengrajin gula semut perlu dilakukan, seperti Mustaufik dkk Produk gula semut beriodium yang dihasilkan oleh pengrajin gula kelapa KSU Liga Sirem Desa Sikapat, Sumbang Banyumas ini telah sesuai dengan standar mutu yang ditetapkan oleh SNI- SII.0268-95 dan Depkes RI dan Program pengembangan usaha gula semut beriodium ini telah memberikan dampak positif terhadap peningkatan kesehatan dan pendapatan (kesejahteraan) di kalangan pengrajin gula.' Penelitian yang dilakukan Puji dengan melakukan analisis faktor yang mempengaruhi produksi gula kelapa juga penting dilakukan untuk melihat faktor mana yang paling mempengaruhi, hasil yang didapatkan bahan bakar dan biaya produksi menjadi faktor yang terpenting. ${ }^{10}$ Pudyastuti, N. N et all, mengatakan terdapat beberapa faktor internal, ekternal dan secara umum jumlah sumber daya yang berkualitas masih sangat kurang dapat mempengaruhi pemasaran gula kelapa di Kabupaten Cilacap. Terdapat beberapa alternatif strategi untuk mendukung pengembangan proses produksi dan penjualan Gula Kelapa di Kabupaten Cilacap salah satunya dengan bekerjasama dengan pihak lain. ${ }^{11}$

PT. Pertamina (Persero) memiliki program CSR (Corporate Social Responsibility) yang bertujuan memberikan manfaat yang berkelanjutan bagi masyarakat dan pelestarian lingkungan terutama dalam pembentukan wawasan masyarakat untuk melestarikan lingkungan sekitar. ${ }^{12,13,14,15}$ Program CSR yang

8 Simbolon, Veronika Amelia, Nurmaini Nurmaini, and Wirsal Hasan. 2019. "Pengaruh Pajanan Gas Hidrogen Sulfida (H2S) Terbadap Keluban Saluran Pernafasan Pada Pemulung Di Tempat Pembuangan Akbir (TPA) Ganet Kota Tanjungpinang Tabun 2018." Jurnal Kesehatan Lingkungan Indonesia 18 (1): 42. https://doi.org/10.14710/jkli.18.1.42-49.

${ }^{9}$ Mustaufik, Tobari, and Nurul Hidayat. 2014. "Peningkatan Mutu Produksi Dan Pemasaran Gula Semut Beriodium di Koperasi Serba Usaba (KSU) Ligasirem Sumbang-Banyumas." Riset Akutansi Dan Bisnis 14 (2002): 52-65

10 Puji. 2018. “Analisis Faktor-Faktor Yang Mempengarubi Produksi Gula Kelapa Di Desa Karya Tunas Jaya Kecamatan Tempuling Kabupaten Indragiri Hilir.” Jurnal Agribisnis 7 (1): 1-16.

11 Pudyastuti, Nariswari Novi, Masyhuri Masyhuri, and Any Suryantini. 2019. "Pengembangan Agroindustri Gula Kelapa Di Kabupaten Cilacap: Kajian Strategi Marketing Hasil Pertanian.” Jurnal Kawistara 9 (2): 139. https://doi.org/10.22146/kawistara.39539

12 Supriadinata, Wahyu, and Ak Imanuel Goestaman, S.E., M.Ak. 2013. “Analisis Efektivitas Corporate Social Responsibility (csr) dalam Menyelesaikan Masalab Sosial Lingkungan Perusabaan Studi Kasus pt. Pertamina (persero) Unit Pemasaran TBBM Depot Ende." Calyptra: Jurnal Ilmiah Mahasiswa Universitas Surabaya 2 (1): 1-12 
dilaksanakan PT Pertamina (Persero) Fuel Terminal Maos, berbasis potensi dan budaya lokal yaitu pembuatan gula kelapa dan pada dasarnya ingin menjadi bagian dari proses efektifitas produksi gula sekaligus mengurangi dampak lingkungan dari penggunaan kayu bakar serta mengganti penggunaan sulfit ke bahan baku lainnya. Program ini sejalan dengan program CSR yang dilakukan PT. Pertamina (Persero) lainnya bertujuan memberikan manfaat lebih kepada masyarakat sekitar. Seperti CSR yang dilakukan PT Pertamina Refinery Unit III Plaju, Program ini bergerak pada bidang pengelolaan sampah dari hulu berbasis masyarakat di desa Merbau, Kecamatan Banding Agung, Kabupaten Oku Selatan. ${ }^{16}$

PT. Pertamina (Persero) Gede Bage melaksanakan program CSR dengan Program SEHATI (Sehat Ibu dan Anak Tercinta). Dalam mengimplementasikan Program SEHATI ( Sehat Ibu dan Anak Tercinta) dengan tujuan untuk mengurangi anak yang terkena gizi buruk. ${ }^{17}$ Program PT. Pertamina (Persero) Cabang Bima belum sepenuhnya memberikan dampak positif terhadap pengembangan ekonomi masyarakat, sehingga ProgramProgram yang dilaksanakan belum menciptakan rasa keadilan (fairness) bagi masyarakat sehingga kedepannya program CSR akan terus dilaksanakan guna meningkatkan kesejahteraan masyarakat sekitar karena CSR wajib dilakukan oleh setiap penanam modal sebagaimana diatur dalam Undang-Undang Penanaman Modal (UUPM) Nomor 25 Tahun 2007. ${ }^{18}$

Tahapan pelaksanaan kegiatan dapat dilihat pada gambar di bawah ini, dimulai dari survei untuk mengetahui kondisi dilapangan dimana para penderes masih menggunakan bahan kimia dalam bahan baku gula kelapa, penggunaan bahan bakar kayu dan penggunaan kaleng PVC bekas cat sebagai wadah yang tidak sesuai dengan food grade, tahapan pelaksanaan dengan sosialiasi solusi

13 Disemadi, Hari Sutra, and Paramita Prananingtyas. 2020. "Kebijakan Corporate Social Responsibility (CSR) Sebagai Strategi Hukum Dalam Pemberdayaan Masyarakat Di Indonesia." Jurnal Wawasan Yuridika 4 (1): 1. https://doi.org/10.25072/jwy.v4i1.328

${ }^{14}$ Nayenggita, Gina Bunga, Santoso Tri Raharjo, and Risna Resnawaty. 2019. "Praktik Corporate Social Responsibility (CSR) di Indonesia." Focus: Jurnal Pekerjaan Sosial 2 (1): 61. https://doi.org/10.24198/focus.v2i1.23119.

15 Marthin, Marthen B Salinding, and Inggit Akim. 2018. "Implementasi Prinsip Corporate Social Responsibility (Csr) Berdasarkan Undang-Undang Nomor 40 Tabun 2007 Tentang Perseroan Terbatas." Journal of Private and Commercial Law 1 (1): 111-32. https://doi.org/10.15294/jpcl.v1i1.12358.

16 Puspita, Astri Rica, Agga Arista Barasani, and Rahadiyand Aditya. 2019. "Pengelolaan Program Corporate Social Responsibility (CSR) Pt Pertamina (Persero) Ru Iii Plaju.” Jurnal Empower 4 (1): $29-45$

${ }^{17}$ Gumilar, Sandi, Hadiyanto a. Rachim, dan Lenny Meilanny. 2017. "Tanggung Jawab Sosial Perusahaan (CSR) Studi Efektifitas Program Pt. Pertamina Sehati (Sehat Ibu Dan Anak Tercinta)." prosiding penelitian dan pengabdian kepada masyarakat 4 (2): 235-40. https://doi.org/10.24198/jppm.v4i2.14291

${ }^{18}$ Fitrah, Muhammad. 2015. "Pelaksanaan Corporate Social Responsibility Di PT . Pertamina ( Persero ) Cabang Bima.” Jurnal Kajian Hukum dan Keadilan 3 (2): 264-81. 
pemecahan masalah yang dialami Pendekar hingga di tahap akhir evaluasi dan pembuatan laporan.

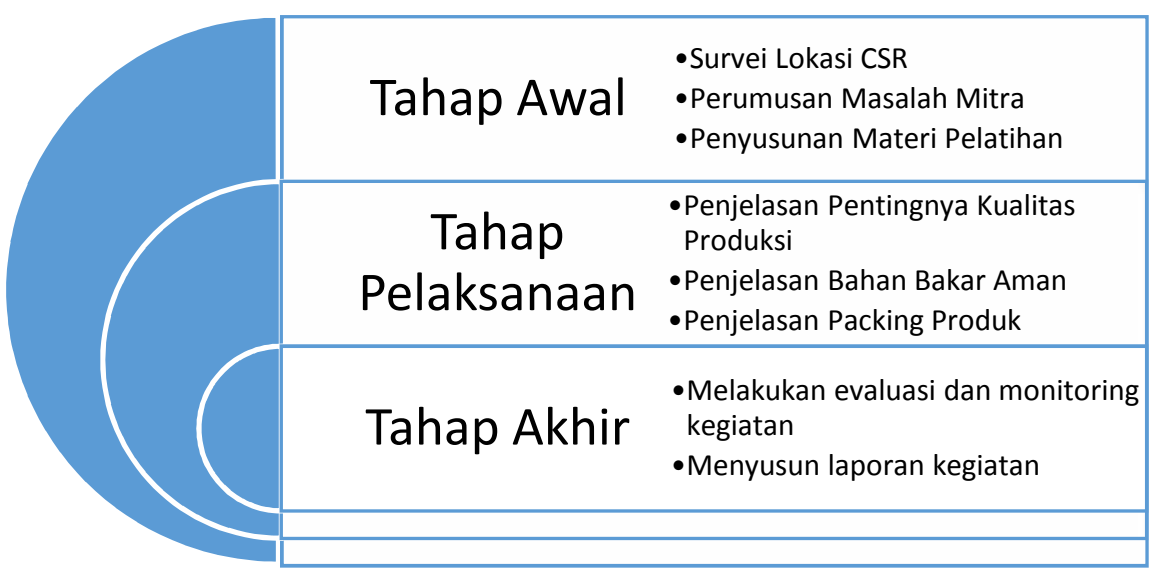

Gambar 1. Tahapan Kegiatan CSR

\section{Hasil dan Pembahasan}

Pelaksanaan program CSR dari PT Pertamina (Persero) Fuel Terminal Maos, berbasis potensi dan budaya lokal yaitu Pembuatan Gula Kelapa di Desa Karangsari Kecamatan Adipala, Kabupaten Cilacap dengan nama Pendekar (Penderes Badek Karangsari). Alasan pemilihan kelompok Pendekar, karena potensi pasar baik dalam negeri hingga ekspor cukup besar bagi produksi gula kelapa, perlunya menjaga kualitas produksi dan pelayanan kunci utama untuk pemasaran yang lebih luas lagi. ${ }^{19,20}$

Terdapat beberapa permasalahan yang dihadapi kelompok penderes Desa Karangsari yaitu :

a. Masih menggunakan bahan kimia Sulfid yang jika dalam pengguanaanya tidak sesuai takarannya akan memiliki dampak buruk jangka panjang jika dikonsumsi secara terus menerus.

b. Penderes tradisional menggunakan kayu bakar untuk memasak gula. Dampak yang ditimbulkan yaitu banyaknya kayu yang ditebang untuk memproduksi gula.

c. Penderes dalam proses menderes nira kelapa selama ini menggunakan kaleng PVC bekas cat, dimana kaleng tersebut tidak memenuhi standar food grade. Sehingga mempersulit saat akan diverifikasi organik.

19 Hardiyanto, Tito. 2020. "Profitabilitas Dan Peluang Pengembangan Agroindustri Gula Kelapa Dalam Sistem Agribisnis Kelapa ( Cocos Nucifera L.) ( Suatu Kasus Di Desa Sukanagara Kecamatan Lakbok Kabupaten Ciamis )". Agritekh (Jurnal Agribisnis dan Teknologi Pangan 1 (1): 46-58.

20 Wardhana, Irawan Wisnu, and M.Arief Budihardjo. 2019. "Pembuatan Gula Semut Kelapa Jahe Di Desa Ujung-Ujung Kec.Pabelan Kab.Semarang.” Jurnal Pasopati 1 (2): 51-55. 


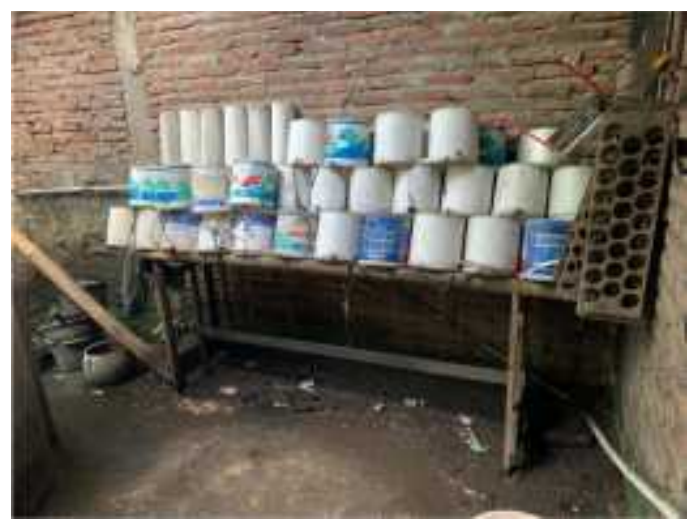

Gambar 2. Kaleng Bekas cat yang digunakan sebagai pongkor, tidak memenuhi standar food grade.

Sebagai perhitungan bila 20 liter nira kelapa biasanya dimasak menggunakan kayu bakar selama 325 menit ( 5,42 jam) akan menghabiskan sekitar 27,2 Kg kayu bakar. Dan berapa kayu bakar yang diperlukan untuk proses produksi selama satu bulan. Hal ini tentu dapat merusak lingkungan sekitar dengan maraknya penebangan pohon guna produksi Gula Kelapa (Jumadil, Rachman, and Hapid 2018). Untuk mengantisipasi hal tersebut Pertamina Fuel Terminal Maos menginisiasi untuk mengkonversi ke bahan bakar gas yaitu LPG $12 \mathrm{~kg}$.

Proses pemberian kompor sebagai bagian dari proses konversi kayu bakar ke gas juga dilaksanakan oleh Pertamina Fuel Terminal Maos. Berdasarkan ujicoba konversi oleh PT Pertamina Fuel Terminal Maos, SBM IV, PT Gelora Tirta Putra, PT Sumber Rejeki Manis dan Mitra Penderes, dengan skema yang sama 20 liter nira kelapa mengkonsumsi $2 \mathrm{~kg}$ gas LPG dan waktu lebih cepat yaitu 98 menit (1 jam 38 menit) selisihnya hingga 277 menit jika dibandingkan menggunakan kayu bakar.

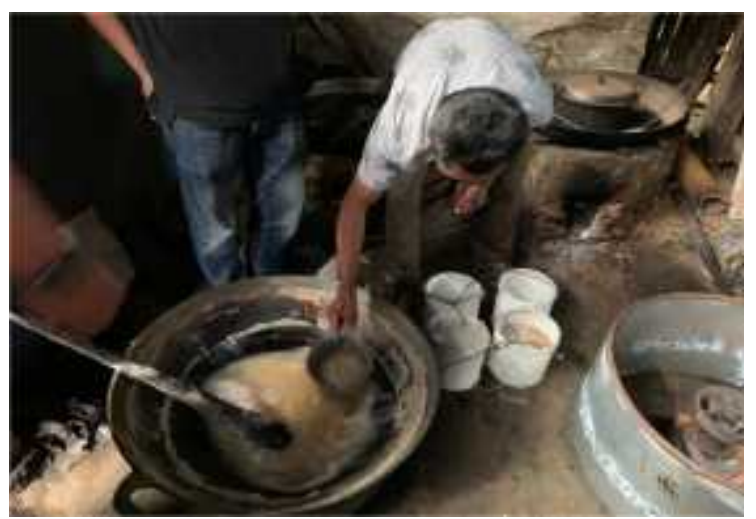

Gambar 3. Proses memasak Gula Kelapa saat ujicoba konversi ke kompor gas LPG 
Untuk mengatasi masalah penggunaan kaleng PVC bekas cat guna mendukung proses produksi dan jangkauan penjualan yang lebih luas, PT Pertamina Fuel Terminal maos membantu penggantian kaleng cat yang digunakan sebagai pongkor tersebut menggunakan pongkor food grade sebanyak 2000 buah dengan kapasitas 4 liter per-pongkor. Kegiatan ini berkejasama dengan Koperasi Nira Cahaya Sejahtera sebagai pihak ketiga yang membina dan menaungi Kelompok Pendekar. Kegiatan konversi ini sekaligus menjadi kegiatan CSV (Corporate Shared Value), hasil produksi perusahaan yaitu LPG dapat dimanfaatkan oleh masyarakat sekaligus masyarakat memperoleh margin keuntungan biaya produksi dan waktu produksi gula kelapa yang diharapkan meningkatkan pendapatan penderes kelapa. Serta mengganti penggunaan sulfid ke penggunaan laru (gamping dan tatal nangka) untuk mencegas persepatan fermentasi nira untuk hasil produksi gula yang lebih sehat.

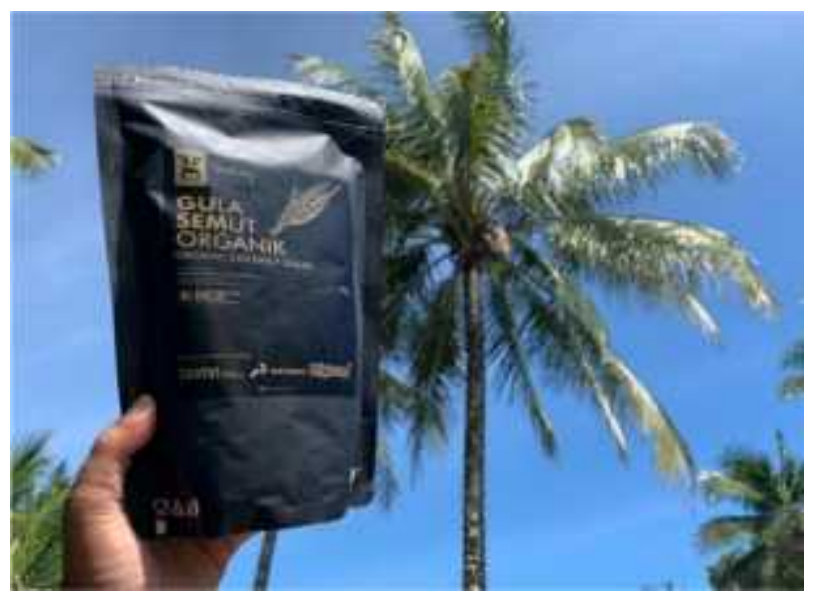

Gambar 5. Produk Gula Semut

Hasil Program CSR PT Pertamina (Persero) Fuel Terminal Maos selanjutnya dikemas dalam untuk mempermudah pemasaran yang lebih luas. Dengan standar pengemasan dan proses produksi yang higienis ditargetkan produk gula semut tidak hanya dipasarkan didalam negeri namun hingga luar negeri. Membangun pasar ke luar negeri dapat menjadi tema pengabdian lanjutkan.

\section{Kesimpulan}

Tujuan dari program CSR (Corporate Social Responsibility) PT. Pertamina (Persero) Fuel Terminal Maos adalah memberikan manfaat yang berkelanjutan bagi masyarakat dan pelestarian lingkungan sekitar. Program ini dilaksanakan bekerja sama dengan Koperasi Nira Cahaya Sejahtera Desa Karangsari yang selanjutnya membentuk program yang disingkat Pendekar (Penderes Badek Karangsari) bertujuan membantu proses produksi dan pemasaran. Kegiatan 
dimulai dengan mengevaluasi proses produksi yang berlanjut pada penggantian bahan bakar, mengganti pongkor food grade hingga mengganti penggunaan bahan kimia sulfid yang berdampak buruk untuk kesehatan ke penggunaan laru. Pengemasan produk juga dibuat lebih menarik dan tahan lama untuk dapat menembus pangsa pasar yang lebih luas.

\section{Daftar Pustaka}

Akolo, Ingka Rizkyani, and Rosdiani Azis. 2018. "Analisis Pengarub Natrium Metabisulfit (Na2S2O5) dan Lama Penyimpanan Terbadap Proses Browning Buah Pir Menggunakan Rancangan Faktorial." Jurnal Technopreneur (JTech) 5 (2): 54. https://doi.org/10.30869/jtech.v5i2.137.

Disemadi, Hari Sutra, and Paramita Prananingtyas. 2020. "Kebijakan Corporate Social Responsibility (CSR) Sebagai Strategi Hukum Dalam Pemberdayaan Masyarakat Di Indonesia." Jurnal Wawasan Yuridika 4 (1): 1. https://doi.org/10.25072/jwy.v4i1.328.

Fitrah, Muhammad. 2015. "Pelaksanaan Corporate Social Responsibility di PT . Pertamina ( Persro ) Cabang Bima." Jurnal Kajian Hukum Dan Keadilan 3 (2): 264-81.

Gumilar, Sandi, Hadiyanto A. Rachim, and Lenny Meilanny. 2017. "Tanggung Jawab Sosial Perusahaan ( CSR ) Studi Efektifitas Program Pt. Pertamina Sehati (Sehat Ibu Dan Anak Tercinta)." Prosiding Penelitian Dan Pengabdian $\begin{array}{llll}\text { Kepada } & \text { Masyarakat } & 4 & \text { 235-40. }\end{array}$ https://doi.org/10.24198/jppm.v4i2.14291.

Hardiyanto, Tito. 2020. "Profitabilitas Dan Peluang Pengembangan Agroindustri Gula Kelapa Dalam Sistem Agribisnis Kelapa (Cocos Nucifera L . )" Agritekh (Jurnal Agribisnis Dan Teknologi Pangan) 1 (1): 46-58.

Hromly. 2019. "Gula Semut Cilacap di Eksport Ke Belanda." Https://Jatengprov.Go.Id/. 2019. https://jatengprov.go.id/beritadaerah/gula-semut-cilacap-di-eksport-kebelanda/.

Joseph, G H, and Payung Layuk. 2012. "Pengolahan Gula Semut Dari Aren." Buletin Palma 13 (1): 60-65. https://doi.org/10.21082/bp.v13n1.2012.6065.

Jumadil, Imran Rachman, and Abdul Hapid. 2018. "Analisis Penggunaan Kayu Bakar Masyarakat Di Dusun Salena Kelurahan Buluri Kecamatan Ulujadi Kota Palu." Jurnal Warta Rimba 6 (3): 21-27.

Marthin, Marthen B Salinding, and Inggit Akim. 2018. "Implementasi Prinsip Corporate Social Responsibility (Csr) Berdasarkan Undang-Undang Nomor 40 Tabun 2007 Tentang Perseroan Terbatas." Journal of Private and Commercial Law 1 (1): 111-32. https://doi.org/10.15294/jpcl.v111.12358.

Mustaufik, Tobari, and Nurul Hidayat. 2014. "Peningkatan Mutu Produksi Dan Pemasaran Gula Semut Beriodium Di Koperasi Serba Usaha (KSU) Ligasirem Sumbang-Banyumas." Riset Akutansi Dan Bisnis 14 (2002): 52-65. 
Nayenggita, Gina Bunga, Santoso Tri Raharjo, and Risna Resnawaty. 2019. "Praktik Corporate Social Responsibility (Csr) Di Indonesia." Focus: Jurnal Pekerjaan Sosial 2 (1): 61. https://doi.org/10.24198/focus.v2i1.23119.

Pratama, F., W.H. Susanto, and I. Purwantiningrum. 2015. "Pembuatan Gula Kelapa Dari Nira Terfermentasi Alami (Kajian Pengarub Konsentrasi Anti Inversi Dan Natrium Metabisulfit)." Jurnal Pangan Dan Agroindustri 3 (4): 1272-82.

Pudyastuti, Nariswari Novi, Masyhuri Masyhuri, and Any Suryantini. 2019. "Pengembangan Agroindustri Gula Kelapa Di Kabupaten Cilacap: Kajian Strategi Marketing Hasil Pertanian.” Jurnal Kawistara 9 (2): 139. https://doi.org/10.22146/kawistara.39539.

Puji. 2018. “Analisis Faktor-Faktor Yang Mempengarubi Produksi Gula Kelapa Di Desa Karya Tunas Jaya Kecamatan Tempuling Kabupaten Indragiri Hilir." Jurnal Agribisnis 7 (1): 1-16.

Puspita, Astri Rica, Agga Arista Barasani, and Rahadiyand Aditya. 2019. "Pengelolaan Program Corporate Social Responsibility (CSR) Pt Pertamina (Persero) Ru Iii Plaju.” Jurnal Empower 4 (1): 29-45.

Rosanti, Aulia Dewi. 2016. "Pengaruh Penambahan Dosis Natrium Bisulfit Dan Natrium Metabisulfit Terbadap Kualitas Gula Merah Tebu." Jurnal Hijau Cendekia 1 (1): 6-10.

Simbolon, Veronika Amelia, Nurmaini Nurmaini, and Wirsal Hasan. 2019. "Pengarub Pajanan Gas Hidrogen Sulfida (H2S) Terhadap Keluban Saluran Pernafasan Pada Pemulung Di Tempat Pembuangan Akhir (TPA) Ganet Kota Tanjungpinang Tabun 2018." Jurnal Kesehatan Lingkungan Indonesia 18 (1): 42. https://doi.org/10.14710/jkli.18.1.42-49.

Supriadinata, Wahyu, and Ak Imanuel Goestaman, S.E., M.Ak. 2013. "Analisis Efeketivitas Corporate Social Responsibility (CSR) dalam Menyelesaikan Masalah Sosial Lingkungan Perusahaan Studi Kasus PT. Pertamina (Persero) Unit Pemasaran Tbbm Depot Ende." Calyptra: Jurnal Ilmiah Mahasiswa Universitas Surabaya 2 (1): 1-12.

Wardhana, Irawan Wisnu, and M.Arief Budihardjo. 2019. "Pembuatan Gula Semut Kelapa Jahe Di Desa Ujung-Ujung Kec.Pabelan Kab.Semarang.” Jurnal Pasopati 1 (2): 51-55.

Zuliana, Crysse, Endrika Widyastuti, and Wahono Hadi Susanto. 2016. "Pembuatan Gula Semut Kelapa (Kajian PH Gula Kelapa dan Konsentrasi Natrium Bikarbonat)." Jurnal Pangan Dan Agroindustri 4 (1): 109-19. https://jpa.ub.ac.id/index.php/jpa/article/view/311. 
50 | Manhaj: Jurnal Penelitian dan Pengabdian Masyarakat | Vol. 10 No. 1, 2021

Halaman ini sengaja dikosongkan 